\title{
COMMENTARY
}

\section{Normal saline versus colloid solutions for induction of hypothermia: the effect of specific heat capacity on cooling}

\author{
Gary M Idelchik ${ }^{1}$ and Joseph Varon ${ }^{2,3^{*}}$ \\ See related research by Skulec et al., http://ccforum.com/content/17/5/R242
}

\begin{abstract}
The prevention of ischemic injury to preserve both endorgan function and improve neurological recovery by the implementation of therapeutic hypothermia has been well established in the literature. However, not only the means by which body temperature is cooled but also the rate by which target temperature is attained remains an area of continued interest and research. The induction of therapeutic hypothermia to begin the process of body temperature lowering through the infusion of a cold solution intravenously into the body may be one variable that influences not only rapidity of cooling but also subsequent clinical outcome. In a recent issue of Critical Care, Skulec and colleagues compared the induction of therapeutic hypothermia by cold normal saline versus cold colloid solution containing hydroxyethyl starch in a porcine animal model of cardiac arrest, assessing both the rate of temperature change and target temperature achieved, in addition to changes in intracranial pressure.
\end{abstract}

The use of therapeutic hypothermia (TH) in clinical medicine is no longer a rarity. A variety of methods have been implemented in an attempt to cool patients faster [1]. In a recent issue of Critical Care, Skulec and colleagues [2] evaluated the efficacy of cold normal saline as compared with a colloid solution containing hydroxyethyl starch in the induction of $\mathrm{TH}$ in survivors of cardiac arrest by using a porcine animal model of ventricular fibrillation (VF). A 20minute infusion of either $45 \mathrm{mg} / \mathrm{mL}$ of $1^{\circ} \mathrm{C}$ cold normal

\footnotetext{
* Correspondence: joseph.varon@uth.tmc.edu

${ }^{2}$ Critical Care Services, University General Hospital, 2219 Dorrington Street,

Houston, Texas 77030, USA

${ }^{3}$ The University of Texas Medical Branch, 301 University Boulevard, Galveston, Texas 77555, USA

Full list of author information is available at the end of the article
}

saline or $45 \mathrm{mg} / \mathrm{mL}$ of $1^{\circ} \mathrm{C}$ cold colloid solution (Voluven, 6\% hydroxyethyl starch 130/0.4 in normal saline; Fresenius Kabi AG, Bad Homburg, Germany) was administered following 5 minutes of VF and subsequent resuscitation. Comparison of pulmonary blood temperature and cerebral blood temperature demonstrated a statistically significant decrease in temperature in animals given normal saline $\left(-2.1 \pm 0.3\right.$ versus $-1.6 \pm 0.2^{\circ} \mathrm{C}$, and $-1.7 \pm 0.4$ versus -1.1 $\pm 0.3^{\circ} \mathrm{C}, P<0.05$, respectively). Moreover, initiation of $\mathrm{TH}$ with normal saline resulted in accelerated cooling when compared with colloid solution $(-91 \pm 22$ versus -68 $\pm 23^{\circ} \mathrm{C} / \mathrm{min}, P=0.046$ ). The authors also performed a mechanical substudy evaluating the specific heat capacities of each fluid and demonstrated that normal saline resulted in statistically more significant cooling than the studied colloid solution $\left(-7,155 \pm 647\right.$ versus $-5,733 \pm 636^{\circ} \mathrm{C} / \mathrm{min}$, $P=0.008$ ), and this is consistent with the above clinical in vivo findings.

These results demonstrating the differential cooling of normal saline compared with a colloid solution containing hydroxyethyl starch both in vivo and experimentally by Skulec and colleagues are both novel academically and consistent with the understanding of specific heat capacity of solutions following the addition of solutes from thermodynamics. Briefly, the addition of a solute to a solution results in an increase in the number of particles that can absorb energy and release it as heat, in turn resulting in an increase in the temperature of the solute-solution combination relative to the solution alone when a constant amount of energy is applied [3]. As the authors demonstrated, the thermodynamic effect of adding solute to a solution resulted in statistically significant differences clinically with respect to hypothermia induction and temperatures attained, as well as rapidity of cooling [2].

Interestingly, the intracranial pressure (ICP) was increased in animals treated with cold colloid solution 
containing hydroxyethyl starch as compared with normal saline solution (end infusion ICPs of $25 \pm 5$ and $16 \pm 6 \mathrm{~mm}$ $\mathrm{Hg}$, respectively), which persisted for up to 90 minutes following infusion. The association of increased ICP with hydroxyethyl starch was also demonstrated by Khan and colleagues, who evaluated the combined incidence of delayed cerebral ischemia, hydrocephalous requiring cerebrospinal fluid shunting, and rebleeding in patients following subarachnoid hemorrhage, and demonstrated a statistically significant increase in both the combined endpoint (odds ratio $3.1,95 \%$ confidence interval 1.30 to $7.36, P=0.01$ ) and the incidence of hydrocephalous requiring cerebrospinal fluid shunting (odds ratio 6.1, 95\% confidence interval 1.63 to $22.95, P=0.004$ ) [4]. The increases in both ICP and hydrocephalous requiring cerebrospinal fluid shunting in these two studies are most likely due to changes in cerebrospinal fluid absorption by the arachnoid microvilli related to hydroxyethyl starch.

The use of colloid solutions containing hydroxyethyl starch for volume resuscitation of critically ill patients has been controversial, and the literature suggests both increased mortality and increased need for renal replacement therapy when compared with normal saline, and subsequently the US Food and Drug Administration issued a boxed recommendation to health-care professionals not to use hydroxyethyl starch-containing solutions in patients admitted to the intensive care unit or in patients with preexisting renal dysfunction [5-7]. The ICP increase seen by Skulec and colleagues in animals treated with colloid solution may be, in part, the mechanism associated with increased mortality in patients treated with hydroxyethyl starch solutions. This study not only elucidates the decreased efficacy of colloid solutions containing hydroxyethyl starch compared with normal saline in the induction of $\mathrm{TH}$ in vivo but also provides insight into complications associated with hydroxyethyl starch and re-emphasizes the importance of specific heat capacity of the solution with respect to rapidity of cooling during $\mathrm{TH}$ induction.

\section{Abbreviations \\ ICP: Intracranial pressure; TH: Therapeutic hypothermia; VF: Ventricular fibrillation.}

\section{Competing interests}

The authors declare that they have no competing interests.

\section{Author details}

'Department of Critical Care Services, University General Hospital, 7501 Fannin Street, Houston, Texas 77054, USA. ${ }^{2}$ Critical Care Services, University General Hospital, 2219 Dorrington Street, Houston, Texas 77030, USA. ${ }^{3}$ The University of Texas Medical Branch, 301 University Boulevard, Galveston, Texas 77555, USA.

\section{Published: 18 Mar 2014}

\section{References}

1. Varon J: Therapeutic hypothermia: the race to faster cooling. Resuscitation 2010, 81:373-374
2. Skulec R, Truhlar A, Turek Z, Parizkova R, Dostal P, Hicks S, Lehmann C, Cerny V: Comparison of cold crystalloid and colloid infusions for induction of therapeutic hypothermia in a porcine model of cardiac arrest. Crit Care 2013, 17:R242.

3. Sonntag RE (Ed): Fundamentals of Thermodynamics. 6th edition. Danvers, MA: John Wiley \& Sons, Incorporated; 2003.

4. Khan SA, Adogwa O, Gan TJ, Null UT, Verla T, Gokhale S, White WD, Britz GW, Zomorodi AR, James ML, McDonagh DL: Effect of $6 \%$ hydroxyethyl starch $130 / 0.4$ in $0.9 \%$ sodium chloride (Voluven ${ }^{\circledast}$ ) on complications after subarachnoid hemorrhage: a retrospective analysis. Springer plus 2013, 2:314.

5. Myburgh JA, Finfer S, Bellomo R, Billot L, Cass A, Gattas D, Glass P, Lipman J, Liu B, McArthur C, McGuinness S, Rajbhandari D, Taylor CB, Webb SA, CHEST Investigators; Australian and New Zealand Intensive Care Society Clinical Trials Group: Hydroxyethyl starch or saline for fluid resuscitation in intensive care. N Engl J Med 2012, 367:1901-1911.

6. Zarychanski R, Abou-Setta AM, Turgeon AF, Houston BL, McIntyre L, Marshall $J C$, Fergusson DA: Association of hydroxyethyl starch administration with mortality and acute kidney injury in critically ill patients requiring volume resuscitation: a systematic review and meta-analysis. JAMA 2013, 309:678-688.

7. US Food and Drug Administration: FDA Safety Communication: Boxed Warning on increased mortality and severe renal injury, and additional warning on risk of bleeding, for use of hydroxyethyl starch solutions in some settings. [http://www.fda.gov/BiologicsBloodVaccines/ SafetyAvailability/ucm358271.htm].

$10.1186 / \mathrm{cc} 13771$

Cite this article as: Idelchik and Varon: Normal saline versus colloid solutions for induction of hypothermia: the effect of specific heat capacity on cooling. Critical Care 2014, 18:123 